\title{
Regional cerebral blood flow during hypoglycaemia in children with IDDM
}

\author{
I. T.Jarjour ${ }^{1,2}$, C.M. Ryan ${ }^{3}$, D. J. Becker ${ }^{2}$ \\ ${ }^{1}$ Departments of Medicine (Neurology) and Pediatrics, Allegheny General Hospital, Medical College of Pennsylvania and \\ Hahnemann University (Allegheny Campus), Pittsburgh, Pennsylvania, USA \\ ${ }^{2}$ Department of Pediatrics, Children's Hospital and University of Pittsburgh School of Medicine, Pittsburgh, Pennsylvania, USA \\ ${ }^{3}$ Department of Psychiatry, Western Psychiatric Institute and Clinic, University of Pittsburgh School of Medicine, Pittsburgh, \\ Pennsylvania, USA
}

\begin{abstract}
Summary Hypoglycaemia may cause transient cognitive impairment and neurological deficits that are frequently unilateral. The effect of mild hypoglycaemia (serum glucose level $3.4 \pm 0.1 \mathrm{mmol} / 1$; mean \pm SEM) on regional cerebral blood flow and cerebrovascular resistance was studied in eight right-handed children with insulin-dependent diabetes mellitus (age $14.9 \pm 0.7$ years; diabetes duration $7.4 \pm 1.1$ years; six males) using the intravenous xenon-133 clearance method. Global mean cerebral grey and white matter blood flow, adjusted to mean $\mathrm{pCO}_{2}$ of cohort, showed a trend towards an increase from $54.7 \pm$ $3.5 \mathrm{ml} \cdot 100 \mathrm{~g}^{-1} \cdot \mathrm{min}^{-1}$ at baseline euglycaemia to $58.0 \pm 4.1 \mathrm{ml} \cdot 100 \mathrm{~g}^{-1} \cdot \mathrm{min}^{-1}$ during hypoglycaemia $(p=0.075)$. Statistically significant changes were seen in global mean cerebral grey matter blood flow, as indexed by initial slope, which increased from $88.0 \pm 6.5 \mathrm{~min}^{-1}$ before hypoglycaemia to $96.3 \pm$
\end{abstract}

$7.2 \mathrm{~min}^{-1}$ during hypoglycaemia $(p<0.05)$. Cerebral grey matter blood flow was significantly higher in the right hemisphere compared to the left during hypoglycaemia $(p<0.01)$ but not at baseline euglycaemia. Measurements of global cerebrovascular resistance showed a borderline decrease from $1.64 \pm 0.11$ to $1.54 \pm 0.11 \mathrm{~mm} \mathrm{Hg} \cdot \mathrm{ml}^{-1} \cdot 100 \mathrm{~g}^{-1} \cdot \min ^{-1}(p<$ 0.09 ). In conclusion, mild hypoglycaemia is associated with increases in cerebral blood flow which are greater in grey matter flow indices and in the right hemisphere. We speculate that asymmetrical cerebral blood flow changes may explain the frequent laterality of neurological deficits during severe hypoglycaemia. [Diabetologia (1995) 38: 1090-1095]

Key words Cerebral blood flow, hypoglycaemia, children.
Since the brain derives most of its energy needs from the oxidation of glucose supplied by the peripheral circulation, a reduction of blood glucose supply will usually result in some degree of impairment in brain function [1]. Moderate hypoglycaemia (plasma glucose level of $2.5 \mathrm{mmol} / \mathrm{l}$ ) causes alterations in cognitive [2], neurophysiologic [3, 4], and cerebral circula-

Received: 26 July 1994 and in final revised form: 27 March 1995

Corresponding author: Dr. I.T. Jarjour, Allegheny Neurological Associates, 420 East North Avenue, Suite 206, Pittsburgh, PA, 15212, USA

Abbreviations: IDDM, Insulin-dependent diabetes mellitus; $\mathrm{rCBF}$, regional cerebral blood flow; IS, initial slope; $\mathrm{pCO}_{2}$, end-tidal $\mathrm{CO}_{2} ; \mathrm{CVR}$, cerebrovascular resistance; MABP, mean arterial blood pressure; SPECT, single photon emission computed tomography; ANOVA, analysis of variance. tory functions [5-7] in both diabetic and non-diabetic adults. A greater degree of hypoglycaemia may cause seizures and neurological deficits which are frequently, and for unknown reasons, unilateral [8-11]. More often than not, these "hypoglycaemic strokes" affect the left cerebral hemisphere, leading to rightsided weakness $[10,11]$.

In patients with insulin-dependent diabetes mellitus (IDDM), intensification of diabetes therapy to improve glycaemic control frequently causes mild hypoglycaemia, as plasma glucose concentration declines to $3.3 \mathrm{mmol} / /$ or below [12]. While such glycaemic levels were previously considered normal in adults $[9,13]$, recent research has shown counterregulatory hormone secretion at these levels [14]. Indeed, our group induced transient cognitive impairment in diabetic adolescents when glucose levels were low- 
ered to $3.3-3.6 \mathrm{mmol} / \mathrm{l}$ [15]. On the other hand, adults with IDDM rarely show cognitive deficits until blood glucose values fall below $2.7 \mathrm{mmol} / 1$ [16].

The reason for the difference in vulnerability to hypoglycaemia between children and adults remains unknown. Because children generally exhibit higher regional cerebral blood flow (rCBF) and cerebral metabolic rates than adults [17-19], it is possible that the CBF response to hypoglycaemia in children may also be different from that in adults, and this in turn may account for their apparent decreased tolerance to mild hypoglycaemia. Although variable compensatory increases in rCBF have been found during moderate-to-severe hypoglycaemia (plasma glucose levels of $2.5-1.7 \mathrm{mmol} / \mathrm{l}$ ) in diabetic [6] and non-diabetic $[5,7]$ men, neither the effects of mild hypoglycaemia on rCBF at any age, nor the effects of any degree of hypoglycaemia on $\mathrm{rCBF}$ in children with IDDM, have been evaluated. The only extant study found that during spontaneous moderate hypoglycaemia, neonates showed an increase in mean CBF, relative to euglycaemic subjects [20]. The present study was undertaken to elucidate the effects of mild hypoglycaemia on rCBF in children with IDDM.

\section{Subjects and methods}

Study population. Eight right-handed children with IDDM, aged 12 to 18 years (14.9 \pm 0.7 , mean \pm SEM; six males), were recruited from the Children's Hospital of Pittsburgh Diabetes Registry. Duration of IDDM ranged from 2 to 11 years (7.4 \pm 1.1$)$. Stable $\mathrm{HbA}_{1}$ ranged from 9.2 to $14.4 \%(11.1 \pm 0.7$; normal $=4.9-7.3 \%)$. Three subjects had a history of hypoglycaemic seizures; two had a single seizure more than 1 year earlier, and one had several seizures over a 2-year period, with the most recent one occurring 9 days prior to this study. None of these subjects were being treated with anticonvulsants. One patient had mild background retinopathy and mild arterial hypertension, and one had a history of mild attentiondeficit disorder which did not require pharmacotherapy. All subjects signed an assent and a parent gave written consent. The study was approved by the Human Rights Committee at the Childrens' Hospital of Pittsburgh and the Radiation Safety Committee of the University of Pittsburgh.

Insulin-glucose clamp technique. Subjects were admitted to the General Clinical Research Center at the Childrens' Hospital of Pittsburgh. Intermediate and long-acting insulin therapy was withheld $24-36 \mathrm{~h}$ prior to testing. Euglycaemia was maintained by four injections of regular insulin prior to meals on the day prior to glucose clamp. At 22.00 hours on the night before the clamp, a variable rate intravenous insulin infusion was started and continued until 08.00 hours the next morning in order to maintain overnight euglycaemia. At 08.00 hours, a regular pork insulin infusion was started at $0.1 \mathrm{U} \cdot \mathrm{kg}^{-1} \cdot \mathrm{h}^{-1}$ and continued until the end of the study. The resulting plasma free insulin concentration was maintained at about $90 \mu \mathrm{U} / \mathrm{ml}$ for the duration of the study. A variable rate of $10 \%$ dextrose was infused to manipulate glucose levels measured as arterialized plasma glucose (hand in warm box) every $5 \mathrm{~min}$ from the dorsal vein of the left hand [15]. At the beginning of the study, plasma glucose was clamped at $5.5 \mathrm{mmol} / 1$ for at least $45 \mathrm{~min}$ to achieve a stable euglycaemic baseline. The first rCBF measurement was taken during the last $15 \mathrm{~min}$ of that period and at least $60 \mathrm{~min}$ after the increased insulin infusion. After this, plasma glucose levels were dropped over a $15-\mathrm{min}$ period to approximately $3.4 \mathrm{mmol} / \mathrm{l}$ by decreasing the intravenous glucose infusion. This level was maintained for $60 \mathrm{~min}$; the second rCBF measurement was made during the last $15 \mathrm{~min}$ of this hypoglycaemic nadir. All subjects were returned to euglycaemia during a 15-min period by increasing the glucose infusion rate. Changes from baseline for each subject were evaluated. Because of concerns about excessive radiation exposure that were raised by the Childrens' Hospital of Pittsburgh $\mathrm{Hu}$ man Rights Committee, we were not allowed to measure rCBF during a second euglycaemic control clamp.

Cerebral blood flow measurements. The non-invasive Xe-133 clearance method of Obrist and co-workers [21-23] was used. Following an intravenous injection of $20 \mathrm{mCi}$ bolus of Xe-133 in saline, brain clearance of $\mathrm{Xe}-133$ was monitored for $11 \mathrm{~min}$ using 14 extracranial detectors, seven over each cerebral hemisphere, and a portable rCBF machine (Cortexplorer 16; B.Simonsen Medical, Randers, Denmark). The clearance curves were subjected to two-compartment computer analysis that employed a correction for $\mathrm{Xe}-133$ recirculation estimated from the expired air. This yielded an estimate of the mean flow in grey and white matter, designated $\mathrm{CBF}_{15}$, and an estimate of faster clearing compartment, designated IS (initial slope), which corresponds to cerebral grey matter. End-tidal $\mathrm{CO}_{2}\left(\mathrm{pCO}_{2}\right)$, respiratory and heart rates, haemoglobin, and haematocrit were measured during each rCBF study. Arterial blood pressure was measured by a sphygmomanometer and a cuff. Mean arterial blood pressure (MABP) was calculated as diastolic pressure + one third $\times$ (systolic-diastolic blood pressure). The maximum absorbed radiation dose to the lungs (the target organ) during each $\mathrm{rCBF}$ measurement is $0.08 \mathrm{cGy}$. Other organs receive less than $0.001 \mathrm{cGy}$.

Because of a small but significant decrease in $\mathrm{pCO}_{2}$ during hypoglycaemia $(1.8 \mathrm{~mm} \mathrm{Hg})$ and the independent effect of $\mathrm{pCO}_{2}$ on $\mathrm{rCBF}$, the rCBF data were analysed both before and after adjustment to the mean $\mathrm{pCO}_{2}$ of all the studies (34 $\mathrm{mm} \mathrm{Hg}$ ) [24]. We assumed normal adult $\mathrm{CO}_{2}$ vasoresponsivity in diabetic adolescents (see Discussion) with a $3 \%$ change in $\mathrm{CBF}_{15}$ per $\mathrm{mmHg}$ change in $\mathrm{pCO}_{2}[24,25]: \mathrm{CBF}_{\mathrm{a}}=\mathrm{CBF}_{\text {obs }}$ ! [1- $\left.\left(34-\mathrm{pCO}_{2}\right) \times 0.030\right]$, where $\mathrm{CBF}_{\mathrm{a}}$ is adjusted $\mathrm{CBF}_{15}$ and $\mathrm{CBF}_{\text {obs }}$ is observed $\mathrm{CBF}_{15}$, and $3.5 \%$ change in IS per $\mathrm{mm} \mathrm{Hg}$ change in $\mathrm{pCO}_{2}$ [25]: $\mathrm{IS}_{\mathrm{a}}=\mathrm{IS}_{\text {obs }} /\left[1-\left(34-\mathrm{pCO}_{2}\right) \times 0.035\right]$, where IS $_{\mathrm{a}}$ is adjusted IS and IS $\mathrm{Ibs}_{\mathrm{os}}$ is observed IS. Results of adjusted rCBF data will be presented (i.e., CBF and IS $_{a}$ ) because they decrease variance, and thereby highlight and better illustrate the changes in $\mathrm{CBF}_{\text {obs }}$ and $\mathrm{IS}_{\text {obs }}$ during and after hypoglycaemia [24]. Cerebrovascular resistance (CVR) was calculated as $\mathrm{MABP} / \mathrm{CBF}_{\text {obs }}$. In order to minimize anxiety during rCBF measurements, children underwent a familiarization session the day before testing.

The reproducibility of our rCBF measurements was validated in six adults aged 25 to 30 years (mean \pm SD: $26.6 \pm 2$ years). Four were male; two were IDDM patients, four were not. Each subject underwent two consecutive rCBF measurements, separated by $1 \mathrm{~h}$, using Xe-133 clearance and similar experimental conditions to those during glucose clamps in the reported children's group except that euglycaemia (arterialized plasma glucose of $5.5 \mathrm{mmol} / 1$ ) was maintained during the two measurements. We analysed rCBF data using the same computer software and methods as described above. Mean $\pm \mathrm{SEM}$ of $\mathrm{CBF}_{\mathrm{a}}$ in these adults was $47.4 \pm 4.6$ and $47.2 \pm 3.8 \mathrm{ml} \cdot 100 \mathrm{~g}^{-1} \cdot \mathrm{min}^{-1}$ at times 1 and 2 , respectively. Corresponding initial slope (IS ${ }_{\mathrm{a}}$ ) values were $79.9 \pm 7.3$ 
Table 1. Haemodynamic and physiologic parameters before and during hypoglycaemia

\begin{tabular}{lrr}
\hline & \multicolumn{1}{c}{ Before } & \multicolumn{1}{c}{ During } \\
\hline pCO2 (mm Hg) & $34.6 \pm 0.5$ & $33.8 \pm 0.4^{\mathrm{a}}$ \\
Respiratory rate (breath/min) & $14.8 \pm 0.9$ & $16.1 \pm 0.9$ \\
Haematocrit (\%) & $41.1 \pm 1.1$ & $41.7 \pm 1.0$ \\
Diastolic blood pressure (mm Hg) & $73.4 \pm 3.0$ & $67.9 \pm 3.2^{\mathrm{a}}$ \\
MABP (mm Hg) & $89.1 \pm 2.4$ & $86.0 \pm 2.6^{\mathrm{a}}$ \\
Systolic blood pressure (mm Hg) & $120.6 \pm 4.2$ & $122.1 \pm 1.9$ \\
Heart rate (beats/min) & $78.9 \pm 4.9$ & $78.8 \pm 4.8$ \\
\hline
\end{tabular}

${ }^{a} p<0.05$ compared to values before hypoglycaemia

Values are given as mean $\pm S E M$

and $78.4 \pm 5.7 \mathrm{~min}^{-1}$. Repeated measures analysis of variance shows no significant $\mathrm{CBF}_{\mathrm{a}}$ or $\mathrm{IS}_{\mathrm{a}}$ change over time. Hence, our $\mathrm{rCBF}$ results are highly reproducible under the same experimental conditions.

\section{Statistical analysis}

Statistical analysis of data was carried out using SPSS PC+ v 3.0 software. Paired $t$-test procedures were used to assess hypoglycaemic-induced haemodynamic changes by comparing variables between euglycaemic baseline and hypoglycaemic nadir. Two-factor (Session; Hemisphere) repeated measures analysis of variance (ANOVA) techniques were used, with appropriate contrasts, to determine whether there were significant changes or hemispheric asymmetries in CBF and in cerebrovascular resistance during hypoglycaemia.

\section{Results}

Glucose level was $5.4 \pm 0.3 \mathrm{mmol} / \mathrm{l}$ at baseline and decreased to $3.4 \mathrm{mmol} / 1$ during hypoglycaemia. The effects of hypoglycaemia on various physiologic variables are shown in Table 1. Relative to the euglycaemia at baseline, there was a significant decrease in $\mathrm{pCO}_{2}$ during hypoglycaemia $(p<0.03)$. Respiratory rate did not increase during hypoglycaemia $(p=0.073)$. A non-significant increase in haematocrit during hypoglycaemia was observed $(p=0.052)$. Diastolic and mean arterial blood pressures decreased significantly during hypoglycaemia $(p<0.03$ and $p<$ 0.02 , respectively). Systolic arterial blood pressure and heart rate did not change during hypoglycaemia.

Mean $\mathrm{CBF}_{\mathrm{a}}$ before hypoglycaemia was $54.7 \pm$ $3.5 \mathrm{ml} \cdot 100 \mathrm{~g}^{-1} \cdot \mathrm{min}^{-1}$ and showed a small, non-significant increase during hypoglycaemia (58.0 \pm 4.1 ; $p=0.075$ ). The high degree of intersubject variability in $\mathrm{CBF}_{\mathrm{a}}$ changes during hypoglycaemia is illustrated in Figure 1.

In contrast to the relatively small changes in global grey and white matter flow $\left(\mathrm{CBF}_{\mathrm{a}}\right)$, there were statistically significant increases in grey matter blood flow, as indexed by IS $_{\mathrm{a}}$ values. Mean IS $_{\mathrm{a}}$ increased from $88.0 \pm 6.5 \mathrm{~min}^{-1}$ before hypoglycaemia to $96.3 \pm$ $7.2 \mathrm{~min}^{-1}$ during hypoglycaemia $(p<0.03)$. Marked intersubject variability in IS $_{\mathrm{a}}$ changes during hypoglycaemia was also observed (Fig.2). Five subjects

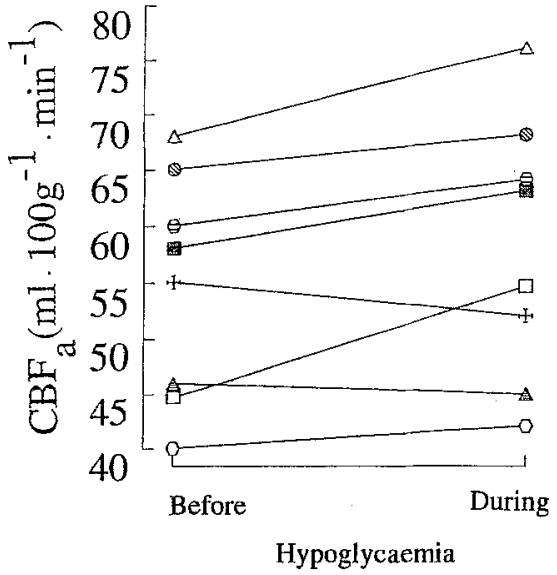

Fig. 1. Individual mean cerebral grey and white matter blood flow $\left(\mathrm{CBF}_{\mathrm{a}}\right)$ values, adjusted to mean $\mathrm{pCO}_{2}$ of cohort, before and during hypoglycaemia in eight children with IDDM

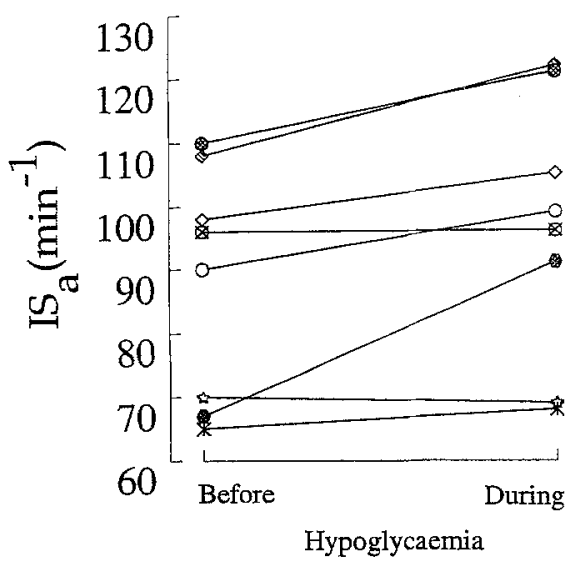

Fig. 2. Individual cerebral grey matter blood flow values, indexed by $\mathrm{IS}_{\mathrm{a}}$ and adjusted to mean $\mathrm{pCO}_{2}$ of cohort, before and during hypoglycaemia in eight children with IDDM

showed increased IS $_{\mathrm{a}}$ during hypoglycaemia and three showed no change. Global CVR showed a small non-significant decrease during hypoglycaemia from $1.64 \pm 0.11$ to $1.54 \pm 0.11 \mathrm{~mm} \mathrm{Hg} \cdot \mathrm{ml}^{-1} \cdot 100 \mathrm{~g}^{-1}$. $\min ^{-1}(p=0.08)$.

In order to explore the relationship between prior glycaemic control and $\mathrm{rCBF}$, we first evaluated the relationship between $\mathrm{HbA}_{1}$ and the increment in $\mathrm{CBF}_{\mathrm{a}}$ and $\mathrm{IS}_{\mathrm{a}}$ and found no significant correlation $(r=$ $-0.24, p>0.50$, and $r=-0.10, p>0.80$, respectively). We then assessed the relationship between $\mathrm{HbA}_{1}$ and actual $\mathrm{CBF}_{\mathrm{a}}$ and $\mathrm{IS}_{\mathrm{a}}$ values during baseline euglycaemia and hypoglycaemia. No significant correlation was found ( $r<0.2, p>0.50$ for all correlations).

Data on hemispheric differences in blood flow and CVR are summarized in Table 2. $\mathrm{IS}_{\mathrm{a}}, \mathrm{CBF}_{\mathrm{a}}$ and CVR were each examined using a two-factor (Hemisphere; Session) repeated measures ANOVA. For the grey matter index ( $\mathrm{IS}_{\mathrm{a}}$ ), there was a main effect of Hemisphere $(p<0.03)$, a main effect of Session $(p<0.03)$, and a Session $\times$ Hemisphere interaction $(p<0.03)$. Subsequent comparisons indicated that the signifi- 
Table 2. Comparisons between right and left cerebral hemispheres before and during hypoglycaemia

\begin{tabular}{llllll}
\hline & \multicolumn{1}{l}{ Before } & & \multicolumn{2}{c}{ During } \\
\cline { 2 - 3 } \cline { 5 - 6 } & Right & Left & Right & Left \\
\hline IS $_{\mathrm{a}}$ & $88.1 \pm 6.4$ & $87.8 \pm 6.6$ & $57.2 \pm 7.4^{\mathrm{a}}$ & $95.3 \pm 7.1$ \\
$\mathrm{CBF}_{\mathrm{a}}$ & $55.0 \pm 3.4$ & $54.4 \pm 3.5$ & $58.6 \pm 4.2$ & $57.4 \pm 4.0$ \\
\hline
\end{tabular}

Significant right vs left hemispheric asymmetry: ${ }^{\mathrm{a}} p<0.01 . \mathrm{CBF}_{\mathrm{a}}$, Cerebral blood flow in $\mathrm{ml} \cdot 100 \mathrm{~g}^{-1} \cdot \mathrm{min}^{-1}$, adjusted; IS , Initial

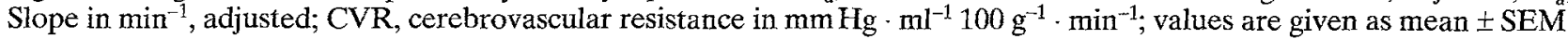

cant right-greater-than-left asymmetrical increase in IS $_{\mathrm{a}}$ was restricted to the hypoglycaemic nadir $(p=0.005)$. Comparisons at baseline $(p>0.50)$ were not statistically significant.

Hemispheric asymmetry was not observed for the combined grey and white matter flow index, $\mathrm{CBF}_{\mathrm{a}}$. There was a main effect of Hemisphere $(p<0.02)$ and a marginal main effect of Sessions $(p=0.051)$, but no interaction $(p>0.10)$.

A main effect of hemisphere was also found for the CVR measure $(p<0.03)$, but there was no main effect of Session $(p>0.08)$ nor a Hemisphere $\times$ Session interaction $(p>0.40)$.

\section{Discussion}

The present study demonstrates that even at mild hypoglycaemic levels, adolescents with IDDM experience variable increases in rCBF. These increases occur at serum glucose levels that are higher (i.e., milder hypoglycaemia) than have previously been reported in adults. Grey matter indices show a greater increase in blood flow than does mean grey and white matter, and the right hemisphere shows a greater increase than the left.

Our findings agree with recent reports of increased rCBF during moderate hypoglycaemia (plasma glucose levels of $2.2 \mathrm{mmol} / \mathrm{l}$ ) in healthy and diabetic adults [5-7], but extend the observation to diabetic children at lesser degrees of hypoglycaemia (glucose levels of $3.4 \mathrm{mmol} / \mathrm{l}$ ). Thus, and contrary to the prevailing belief $[9,13]$, even mild hypoglycaemia can affect $\mathrm{rCBF}$ in diabetic adolescents.

Although our study was not designed to determine glycaemic thresholds for rCBF increases in children, our data suggest a level which is higher than commonly accepted in human adults $(2.5 \mathrm{mmol} / \mathrm{l})$ [26] or awake goats $(2.8-3.0 \mathrm{mmol} / \mathrm{l})$ [27]. Our findings of significant haemodynamic changes during mild hypoglycaemia, such as decreased diastolic and mean arterial blood pressures and a borderline haemoconcentration, suggest effects of counterregulatory hormones at even mild hypoglycaemia. A similar pattern of results has been described in a study showing increases in systolic blood pressure and heart rate in non-diabetic men during severe insulin-induced hypoglycaemia (serum glucose level of $2 \mathrm{mmol} / \mathrm{l}$ ) [28].
Moreover, our group has recently reported significant counter-regulatory hormone secretion at a glucose level of $3.4 \mathrm{mmol} / 1$ [29]. Taken together, these observations suggest that this degree of hypoglycaemia is clinically significant.

The increase in rCBF found in our study was seen predominantly in grey matter flow measures: mean global $\mathrm{CBF}_{\mathrm{a}}$ increased only $4 \%$ but grey matter flow $\left(\mathrm{IS}_{\mathrm{a}}\right)$ increased $9.5 \%$. This observation is consistent with the fact that the outer layers of the cerebral cortex are more sensitive to the effects of hypoglycaemia than deeper layers and white matter $[9,30]$. Moreover, the lesser increase in $\mathrm{CBF}_{\mathrm{a}}$ is probably related to an averaging of slow white matter flow with the normally fourfold faster grey matter flow values [22]. Furthermore, the IS index used in this study is $50 \%$ more sensitive to cortical activation than is the $\mathrm{CBF}_{15}$ index [23]. These data suggest that other quantitative methods to measure rCBF where volume-averaging of grey and white matter occurs, such as positron emission tomography and Xe-133 single photon emission computed tomography (SPECT), may underestimate the effects of hypoglycaemia on rCBF.

Our results are consistent with those reported by Tallroth et al. $[5,6]$ who measured rCBF during moderate hypoglycaemia in 10 non-diabetic and 10 diabetic right-handed men using Xe-133 SPECT and found that global CBF increased in both groups after $10 \mathrm{~min}$ of hypoglycaemia.

To date, the only study of rCBF during hypoglycaemia in children is that reported by Pryds et al. [20], who measured rCBF in 25 pre-term neonates at $2 \mathrm{~h}$ after birth using intravenous Xe-133. They found significant increases in CBF and plasma epinephrine in 13 neonates with blood glucose levels below $1.6 \mathrm{mmol} / \mathrm{l}$. While the increased CBF persisted for more than 30 min after correction of hypoglycaemia, plasma epinephrine levels had reached the baseline level of normoglycaemic neonates. This has led Pryds et al. to suggest that cerebral hyperperfusion during hypoglycaemia is related to mechanisms other than $\beta$-receptor stimulation. In a subsequent study, Skov and Pryds [31] studied cerebral blood volume changes using near-infrared spectroscopy in 18 pre-term newborns during treatment for spontaneous hypoglycaemia (mean blood glucose level $1.2 \mathrm{mmol} / \mathrm{l}$ ) and found decreases in cerebral blood volume after treatment with glucose. They suggested 
that capillary recruitment of previously unperfused capillaries helps maintain glucose transport into neurons of hypoglycaemic, pre-term neonates.

The mechanism underlying the $9.5 \%$ increase in grey matter flow found in this study remains poorly understood. A flow increase of this magnitude, if linear and in already perfused capillaries, would cause only a minimal increase of approximately $3 \%$ in net glucose flux across the blood-brain barrier [32, 33]. This would certainly be inadequate to offset deficits in energy metabolism induced by a blood glucose level of $3.4 \mathrm{mmol} / \mathrm{l}$. This lends support to Skov and Pryds' [31] suggestion of capillary recruitment. Such recruitment would provide a greater possibility of an increase in glucose transport than that permitted by increased linear flow alone [33].

Our observation of asymmetrical hemispheric increases in rCBF during hypoglycaemia is different from the asymmetry reported by Tallroth et al. $[5,6]$. While those authors found higher $\mathrm{rCBF}$ in the right hemisphere compared with the left before and during hypoglycaemia ( 2.3 and $1.6 \%$, respectively in diabetic men, and 2.8 and $1.2 \%$ in non-diabetic men), we found a significant right-greater-than-left hemispheric asymmetry $(p=0.005)$ which was limited to the period of hypoglycaemia $(1.93 \%)$. Hemispheric differences before $(0.52 \%)$ hypoglycaemia were not statistically significant. We have no explanation for the greater $\mathrm{rCBF}$ in the right cerebral hemisphere relative to the left during hypoglycaemia. Such asymmetry was not found by Kerr et al. [7]. These different results may reflect variations across studies in experimental conditions, methodology, or subjects' age. All the subjects in the studies of Tallroth et al. $[5,6]$ and in ours are right-handed, but handedness is not indicated in the report of Kerr et al. [7]. Future studies of left-handed subjects may help clarify the role of cerebral dominance in the observed rCBF asymmetries during hypoglycaemia.

Given the experimental setting of repeated $\mathrm{rCBF}$ measurements in our study, we must consider the possibility that habituation and adaptation to various stimuli during the experiments could account for the pattern of hemispheric asymmetry observed by us. Warach et al. [34] reported a progressive decline in rCBF over time during three consecutive rCBF measurements in young adults using Xe-133 clearance. The decline was attributed to habituation and was limited to right-handed subjects. Moreover, this decline in $\mathrm{rCBF}$ was greater in the left hemisphere relative to the right in males, and in the right hemisphere in females. It is, however, unlikely that habituation can completely explain our results since we found an increase in rCBF over time. Furthermore, our finding of a small, insignificant decline in $\mathrm{rCBF}$ in the euglycaemic adult group is similar to reports from other laboratories on the reproducibility of the Xe-133 clearance method [35-39]. Hence, repeated rCBF measurements using Xe-133 clearance show decreases in rCBF rather an increase, which strongly suggests that the observed increase in $\mathrm{rCBF}$ during hypoglycaemia in our study reflects a true change.

Our finding of an asymmetric $\mathrm{rCBF}$ change during mild hypoglycaemia may explain the frequently observed laterality of neurologic deficits and seizures during severe hypoglycaemia [9-11]. In a review of 29 cases of hypoglycaemic hemiparesis in adults [10], weakness was right-sided in $72 \%$ and left-sided in $28 \%$. Similar right-sided predominance of neurological deficits was observed on 16 of $19(84 \%)$ occasions in seven diabetic children [11]. In none of these reports was there any explanation for such laterality of deficits. Based on our data, we speculate that the left cerebral hemisphere is more susceptible to the deleterious effects of hypoglycaemia because of its decreased ability to increase rCBF.

In analysing results from our study, we adjusted the rCBF data to $\mathrm{pCO}_{2}$ changes due to a small, but significant, decrease in $\mathrm{pCO}_{2}$ during hypoglycaemia $(1.8 \mathrm{~mm} \mathrm{Hg})$. Because of an absence of quantitative data in adolescents, we used adjustment factors based on normal young adults' $\mathrm{rCBF} / \mathrm{CO}_{2}$ reactivity $[24,25]$. It is likely that the magnitude of $\mathrm{rCBF} / \mathrm{CO}_{2}$ reactivity may be slightly different in adolescents. However, this should not affect the trend in rCBF changes or rCBF hemispheric differences. Our findings of a significant increase in right hemispheric blood flow during hypoglycaemia before adjustment of rCBF data, and a borderline decrease in CVR, which was based on observed and not adjusted $\mathrm{CBF}_{15}$ values, lead us to infer that our adjustment of rCBF data to $\mathrm{pCO}_{2}$ should not affect our conclusion of increased CBF during hypoglycaemia.

In conclusion, our pilot study of the effects of mild, experimentally-induced hypoglycaemia on rCBF in eight adolescents with IDDM demonstrated increases in $\mathrm{rCBF}$ which were greater in grey matter blood flow indices than in mean grey and white matter indices. Moreover, there was significant hemispheric asymmetry, with a relatively greater increase in flow in the right hemisphere during hypoglycaemia.

Acknowledgements. The authors wish to thank Ms. T. Williams and Ms. P. Way for technical assistance, Dr. L. Jarjour and Dr. J.Lucke for help with data analysis, Professor W. Obrist for critical review of the manuscript, and the nursing staff of the General Clinical Research Center for excellent assistance during glucose clamps. This work was supported in part by $\mathrm{Na}-$ tional Institutes of Health grants 5 M01 RR00084 and 1 R01HD29487, Diabetes Action Research and Education Foundation grant 001, Juvenile Diabetes Foundation, and the Renziehausen Fund.

\section{References}

1. Robinson PJ, Rapaport SI (1986) Glucose transport and metabolism in the brain. Am J Physiol 250: R127-R136 
2. Hoffman RG, Speelman DJ, Hinnen DA, Conley K, Guthrie $R$, Knapp $R$ (1990) Changes in cortical functioning with acute hypoglycaemia and hyperglycaemia in type I diabetes. Diabetes Care 12: 12-17

3. Pramming S, Thorsteinsson B, Stigsby B, Binder C (1988) Glycaemic threshold for changes in electroencephalograms during hypoglycaemia in patients with insulin dependent diabetes. BMJ 296: 665-667

4. Tamburrano G, Lala A, Locuratolo N et al. (1988) Electroencephalography and visually evoked potentials during moderate hypoglycaemia. J Clin Endocrinol Metab 66: 1301-1306

5. Tallroth G, Ryding E, Agardh C-D (1992) Regional cerebral blood flow in normal man during insulin-induced hypoglycaemia and in the recovery period following glucose infusion. Metabolism 41: 717-721

6. Tallroth G, Ryding E, Agardh C-D (1993) The influence of hypoglycaemia on regional cerebral blood flow and cerebral volume in type 1 (insulin-dependent) diabetes mellitus. Diabetologia 36: 530-535

7. Kerr D, Stanley JC, Barron M, Thomas R, Leatherdale BA, Pickard J (1993) Symmetry of cerebral blood flow and cognitive responses to hypoglycaemia in humans. Diabetologia 36: $73-78$

8. Ehrlich RM (1971) Hypoglycaemia in infancy and childhood. Arch Dis Child 46: 716-719

9. Prockop LD, Wilkinson DS (1976) Hypoglycaemia effects on the central nervous system. In: Vinken PJ, Bruyn GW (eds) Handbook of clinical neurology, Vol 27. Elsevier Publishing Co., New York, pp 53-78

10. Foster JW, Hart RG (1987) Hypoglycaemic hemiplegia: two cases and a clinical review. Stroke 18: 944-946

11. Wayne EA, Dean HJ, Booth F, Tenenbein M (1990) Focal neurologic deficits associated with hypoglycaemia in children with diabetes. J Pediatr 117: 575-577

12. DCCT Research Group (1991) Epidemiology of severe hypoglycaemia in the Diabetes Control and Complications Trial. Am J Med 90: 450-459

13. Sieber FE, Traystman RJ (1992) Special issues: glucose and the brain. Crit Care Med 20: 104-114

14. Gerich JE, Campbell PJ (1988) Overview of counterregulation and its abnormalities in diabetes mellitus and other conditions. Diabetes Metab Rev 4: 93-111.

15. Ryan CM, Atchison J, Puczynski S, Puczynski M, Arslanian S, Becker D (1990) Mild hypoglycaemia associated with deterioration of mental efficiency in children with insulin dependent diabetes mellitus. J Pediatr 117: 32-38

16. Mokan M, Mitrakou A, Veneman T et al. (1994) Hypoglycaemia unawareness in IDDM. Diabetes Care 17: 13971403

17. Chugani HT, Phelps ME, Mazziota JC (1987) Positron emission tomography study of human brain functional development. Ann Neurol 22: 487-497

18. Kennedy C, Sokoloff L (1957) An adaptation of the nitrous oxide method to the study of the cerebral circulation in children; normal values for cerebral blood flow and cerebral metabolic rate in childhood. J Clin Invest 36: 1130-1137

19. Ogawa A, Sakurai Y, Kayama T, Yoshimoto T (1989) Regional cerebral blood flow with age: changes in $\mathrm{rCBF}$ in childhood. Neurol Res 11: 173-176

20. Pryds O, Christensen NJ, Friis-Hansen B (1990) Increased cerebral blood flow and plasma epinephrine in hypoglycaemic, preterm neonates. Pediatrics 85: 172-176

21. Obrist WD, Thompson HK, Wang HS, Wilkinson WE (1975) Regional cerebral blood flow estimated by 133 xenon inhalation. Stroke 6: 245-256
22. Obrist WD, Wilkinson WE (1990) Regional cerebral blood flow measurements in humans by xenon-133 clearance. Cerebrovasc Brain Metab Rev 2: 283-327

23. Obrist WD, Wilkinson WE (1985) Stability and sensitivity of $\mathrm{CBF}$ indices in the noninvasive ${ }^{133} \mathrm{Xe}$ method. In: Hartmann A, Hoyer S (eds) Cerebral blood flow and metabolism measurement. Springer Berlin Heidelberg New York, pp 30-36

24. Hoedt-Hasmussen K (1967) Regional cerebral blood flow. The intra-arterial injection method. Acta Neurol Scand 43 [Suppl 27]: 39-41

25. Marion DW, Obrist WD, Coulier PM, Peurod LE, Darby JM (1993) The use of moderate therapeutic hypothermia for patients with severe head injuries: a preliminary report. J Neurosurg 79: 354-362

26. Fox PT, Raichle ME, Mintun MA, Dence C (1988) Nonoxidative glucose consumption during local physiologic neural activity. Science 241: 462-464

27. Gomez B, Garcia-Villallon AL, Frank A, Garcia JL, Monge L, Dieguez G (1992) Effects of hypoglycaemia on the cerebral circulation in awake goats. Neurology 42 : 909-916

28. Hilsted J, Bonde-Petersen F, Norgaard M-B et al. (1984) Haemodynamic changes in insulin-induced hypoglycaemia in normal man. Diabetologia 26: 328-332

29. Geschwend S, Ryan CM, Atchison J, Arslanian S, Becker D (1995) Effects of acute hyperglycaemia on mental efficiency and counter-regulatory hormones in adolescents with insulin-dependent diabetes mellitus. J Pediatr 126: 178-184

30. Auer RN (1986) Progress review: hypoglycaemic brain damage. Stroke 17: 699-708

31. Skov L, Pryds O (1992) Capillary recruitment for preservation of cerebral glucose influx in hypoglycaemic, preterm newborns: evidence for a glucose sensor? Pediatrics 90: 193-195

32. Crone C (1980) Substrate supply to the brain. In: Parvez $H$, Parvez S (eds) Advances in experimental medicine: a centenary tribute to Claude Bernard. Elsevier/North Holland Biomedical press, Amsterdam, pp 319-349

33. Lund-Andersen H (1979) Transport of glucose from blood to brain. Physiol Rev 59: 305-352

34. Warach S, Gur RC, Gur RE, Skolnick BE, Obrist WD, Reivich $M$ (1992) Decreases in frontal and parietal lobe regional cerebral blood flow related to habituation. J Cereb Blood Flow Metab 12: 546-553

35. Wilkinson IMS, Bull JWD, DuBoulay GH, Marshall J, Ross Russell RW, Symon L (1969) Regional blood flow in the normal cerebral hemisphere. J Neurol Neurosurg Psychiat 32: $367-378$

36. Blauenstein UW, Halsey JH, Wilson EM, Wills EL, Risberg J (1977) ${ }^{133}$ Xenon inhalation method. Analysis of reproducibility: some of its physiological implications. Stroke 8: 92-102

37. Thomas DJ, Zilkha E, Redmond S et al. (1979) An intravenous ${ }^{133}$ Xenon clearance technique for measuring cerebral blood flow. J Neurol Sci 40: 53-63

38. Prohovnik I, Hakansson K, Risberg $J$ (1980) Observations on the functional significance of regional cerebral blood flow in "resting" normal subjects. Neuropsychologia 18: 203-216

39. Schroeder T, Holstein P, Lassen NA, Engell HC (1986) Measurement of cerebral blood flow by intravenous Xenon-133 technique and a mobile system: reproducibility using the Obrist model compared to total curve analysis. Neurol Res 8: 237-242 